\title{
An IBM 357 Circulation Procedure
}

This paper describes an IBM 357 circulation system for a mediumsized university library. Equipment needs are enumerated, necessary procedures are outlined, conversion requirements are delineated. The occasional need for integrated manual input is taken into account, and problems of cost are discussed. The role of a 357 program in a totally automated system is also commented upon.

$\mathrm{T}$

I HE AIM of this paper is to describe and comment upon the use of an IBM 357 system in a university library circulation procedure, in terms of planning, installation, cost, data processing routines, and circulation procedures.

Certain factors are assumed at the outset: first, that the university library in question has a collection of seven hundred thousand volumes and an annual budget of $\$ 1$ million. Second, that punched student identification cards are already in use on campus; and finally, that shared time is available on a university-owned and -operated computer. System costs would rise sharply if the expense for either of the latter two items were to be borne by the library.

The 357 system is expensive to install and relatively so to operate, but once established it is rapid and accurate. It virtually eliminates the most notorious causes of error and disorder in a library circulation file-hand filing and pulling of cards and repeated transcription of call number information-since call number and borrower information are reproduced automatically from punched system inputs. Borrower participation in the charging process is, of course, completely eliminated.

One theory is that the cost of automa-

Mrs. Stockton is Head of the Acquisitions Department in the American University Library, Washington, D.C. tion will at some point prove less expensive than continuing a manual system. This thesis is heartily endorsed by data processing firms, but since no automatic system has operated over a long enough period to make accurate cost comparisons, it remains a moot point.

In terms of service, however, there is no doubt that this system is superior to. any manual or semi-automated procedure; it permits a volume of operation which would cause a manual system to break down. Therefore, accuracy, speed, and increased service, rather than economy, are benefits which may be anticipated from its installation.

The system is expected to provide certain end products: an accurate circulation file in correct call number order; rapid updating of that file; automatic processing of overdue books; capability to "hold" a book which was circulating when requested; and preparation of whatever library statistics are desired. As a corollary to these end products, there is access to the circulation file by borrower identification number, call number, or date due.

The components of the 357 configuration are as follows:

357 input station, model 6. Student badge and book card accepted as input. Its brushes sense the punches in the master book card and identification badge and convert them 
into electrical impulses which are transmitted to the 358 control unit. It also sends date-due information from the 374 cartridge reader.

358 control unit. The little black box which acts as liaison between the input station and the 026 keypunch.

374 cartridge reader. Provides variable due date information. It accepts little square cartridges, each with numbers which slide up and down and can be locked in place. The cartridges fit into a slot in the upper portion of the 374 . To change a due date, the old cartridge is slid out and the new slipped in. ${ }^{1}$

026 keypunch. By grace of special controls, it accepts electrical signals from the 358 control unit and translates them into impulses which cause punches to be made in blank IBM cards.

In addition, an off-line computer is needed to update the circulation file and to process overdues. Punched card equipment could be used, but it is cumbersome, inefficient, and expensive.

The system accepts two inputs, the borrower identification badge and the master book card. The borrower card is made of plastic and is the size of a gasoline credit card. It contains a photograph of the borrower, his name and identification number printed in embossed machine readable language, and the identification number in machine language (punched). The identification number is the borrower's social security number prefaced by a single digit which identifies him as student, faculty, faculty spouse, staff or special borrower. Where possible identification cards

\footnotetext{
1 The 372 manual entry keyboard may be used as an alternative to the 374 . It rents for only $\$ 16.00$ per month, as opposed to $\$ 20.00$ for the cartridge reader plus $\$ 4.00$ for each cartridge. The date due is set by screws under the face of the machine which must be reset each time the date due changes, making it impractical to have more than a single due date for all borrowers.
}

should be produced by a central university office, not by the library. This spares the library the time and expense of processing one more document; besides, the ID cards can be used for other university purposes. The cards are of two types, permanent and temporary. Temporary cards have expiration dates stamped on their faces. Permanent cards are to be validated each semester or accompanied by a document which proves the current status of the borrower. Unless the card is valid, the borrower may not charge books.

The master book card is a plasticcoated IBM product; it contains the complete punched call number of the book, as well as signal punches which activate the card reader, badge reader, and cartridge reader and a check digit designating a valid transaction. The call number is printed at the top left of the card so that the circulation attendant may spot check it against the book in hand.

System output is dual: a yellow charge card which is retained by the library, and a pink return card which goes with the book and serves to remind the student of the date due. Each of these cards has punched into it the call number of the book, borrower identification number, date due, a validation punch, and a card identification punch.

\section{Conversion to 357 System}

Assuming that punched student cards are already in use, the first, most timeconsuming, and moşt costly procedure is preparation of the master book dards. This should begin at least a year before the system is expected to begin operating. If the book cards are ready sooner, the system can begin operating earlier.

The first step is to code each shelflist card onto a special sheet which can be mechanically scanned by a mark sense device. This coding may be done by student assistants. The sheets are 
marked with machine readable pencil, circling the proper letters and numbers, and utilizing as many cards as necessary to differentiate between similar volumes with different dates, years, etc. The first card is filled in completely. Cards two through eight are numbered sequentially and left blan down to the appropriate spot (volume number, date, or part). After the sheets are complete they are mark sensed and a tape is produced from them. The tape is returned to the university and the university computer punches the book cards directly from it. The information has been recorded only once, drastically reducing transcription errors.

After the book cards have been punched they must be inserted in the books, producing the somewhat mixed blessing of a complete inventory. If a volume cannot be located the shelf list should be consulted; either the number has been coded incorrectly or the volume is missing.

Concurrently with preparation of the book cards an initial effort should be made to acquaint the staff with the new system: why it is being installed, etc. This will give staff members opportunity to offer constructive criticism before the system becomes operative.

Data processing programs should be developed during this period so that there will be ample time to review and revise them. Space requirements will also need to be examined and if necessary the location of the circulation area changed. For a library of this size at least four input stations are necessary. They may be set up as two systems, each system consisting of two input units back to back, joined by a 358 control unit and connected to an 026 keypunch. None of these machines is undersized and each needs a free work and repair area around it.

The machines are connected to each other and to a main transmission line by cable. Each station requires a 115 volt, 60 cycle, single phase power receptacle, grounded. As well, each cable connection to the main transmission line requires a junction box. A certain amount of cable is supplied by IBM. The library provides the rest in addition to the main transmission line, the electric outlets, and the junction boxes. All of the cabling and electric work must be installed and tested before the machines are installed.

Finally it remains to train the circulation staff in its new procedures and to review the system in detail with the entire staff. The system is then ready for operation.

\section{Circulation Procedures}

To charge a book, the student badge is inserted into the "badge read" portion of the 357 input station, the book card is placed in the "card read" portion of the same unit, and the correct cartridge is slipped into the 374 cartridge reader. With luck, the "in process" light will come on and transmission will begin. If the "repeat" light comes on, either the date due was not inserted properly, the keypunch is not ready to receive (no card in "read" position), or the keypunch stacker is full and needs to be emptied. If these three possibilities are investigated and the machine still does not work, it is time for a call to the IBM adjustment engineer. As the transmission is successfully completed, two cards are punched automatically by the 026 keypunch. The return card is placed inside the book with the master book cald while the charge card may be left in the 026 stacker temporarily. Later these cards are dropped into the day's circulation file, in no particular order. The borrower identification badge is returned to him with the book.

To discharge a book, the circulation attendant merely removes the return 
card, drops it into the "return" file, and the book is ready to be shelved.

Each evening the circulation file is taken to data processing, where it is arranged in call number sequence by the computer. Overdues are prepared simultaneously, either daily or at $X$ intervals. The outstanding file is processed, and the date on each card is compared with the current date. If the due date is earlier, the volume is overdue and that recòrd is written onto a separate overdue tape. At the same time the computer causes an asterisk to be printed at the end of the original tape record. A second asterisk on the tape causes a phrase to be added to the overdue notice, "final notice; your next notice will be a bill." The overdue tape is next matched against the appropriate address file (determined by the first digit of the borrower number), the fine is computed, and the notices are printed on continuous post-card stock, stamped, and mailed.

If the charge record already contains two asterisks, showing that two overdue notices have already been sent, a fines notice is processed and sent. Fines notices are produced in triplicate; one copy is sent to the borrower, one to the university registrar or controller, and the third to the library, where it is filed at the circulation desk by borrower number. When the fine is paid, that card must be pulled by hand and sent to the university authority to clear the student's record.

When overdue books are returned and their fines paid at the desk, those return cards are held in a separate file. They are delivered separately to data processing each evening to be gang punched (an $\mathrm{X}$ in column 79) showing that their fines have been paid. The computer will not print fines notices for these volumes. If a book is turned in and a fine is not paid, no attempt is made to find out if it is overdue. The computer will auto- matically process the record and prepare the proper control cards.

\section{Manual Charges}

If the item circulating is not classified or if its master book card has been lost, it will have to be charged manually. For this purpose a manual charge set is used consisting of two parts, an original slip and a card-stock carbon. The form contains a space for the borrower name and identification number, date due, title and, if necessary, the call number of the book. Student name and number are imprinted on the charge set from the printed portion of the identification card by an electric Dashew machine. The date due and other information are filled in by hand.

If the item is unclassified (record, periodical) the title is written in the left hand portion of the charge set. The original slip is placed inside the item as a return slip. The card stock carbon is filed separately and sent to data processing each evening, ito be punched and filed by title. This assures that overdue notices will be sent for non-classified items. When the item is returned its slip is removed, filed separately and sent to data processing, where a return card is produced to cancel the charge card and tape record.

If the item is classified and its book card is missing, the right side of the form is filled out-with the complete call number of the book. The left side (title) is left blank. The original slip goes with the book as a return slip; the card stock carbon is sent to data processing, which punches a new master card, a charge card, and a return card. The charge card is interfiled mechanically in the regular circulation file; the return card and master book card are filed together in a separate file specifically for cards of this type. When the book is returned, these cards must be hand pulled, the new master book card inserted in the 
book, and the return card sent to data processing as usual to clear the charge card and tape.

\section{Personal Reserves}

When a borrower wishes to request a book which is charged out, he places a hold on the book at the circulation desk by filling out a manual charge set with his name and address, the call number of the book and the notation "hold." The original slip of the charge set is either given to the borrower or discarded and the card stock goes to data processing, where it is matched against the record; "hold" is noted on the record by a special identifying punch. When the book is returned, those charge cards which have "hold" punches are sorted out separately and returned immediately to circulation. The book is retrieved, and the borrower is notified by the circulation staff that it is being held for him.

\section{Course Reserve}

If reserves and circulation are combined, the same machines and personnel can be used for both. The merger goes hand in glove with an attempt to cut down on the number of books placed on reserve. Reserve books are numbered serially, 1-x. as they are processed for the reserve shelf. The borrowers request them by reserve number, which is obtained from IBM printouts, one set by author, another by professor. In charging reserves, the Dashew machine is used to imprint borrower information and date due; the number of the reserve book is printed by hand on the charge card (virtually any type of card will do) and the cards are filed by reserve number in a small file kept at the reserve section of the circulation area.

\section{Projected Cost}

It is virtually impossible to make a meaningful estimate of how much it will cost to put this system into operation. The most expensive element is preparation of the book cards, which is performed by student assistants; their wages will vary according to the location of the library. In addition, the salaries of circulation employees and of forms must be costed. Each individual library will have its own peculiarities; some items will be less expensive than expected, others much higher. Southern Illinois University library, which installed a 357 system, estimated that it cost $\$ 40,000$, excluding salaries, to develop. The only really firm figures are machine rentals and IBM card costs:

\section{Machine Rental:}

357 input station, model 6 . . \$ $\$ 35.00$ per month 358 control unit . . \$79.00 per month 207 cartridge reader $\$ 20.00$ per month cartridges, each . \$ 4.00 per month 026 keypunch . . . \$60.00 per month with necessary controls, additional $\$ 30.00$ per month

\section{IBM CARDS:}

$\$ 1.05$ per 1,000 for quantities of 20,000 or more, printed on one side, any color.

Assuming circulation averages 1,500 per day: 3,000 cards per day 90,000 per month; $\$ 90.00$ per month = $\$ 100.00$ per month, minimum.

\section{System in the Context of A Totally Automated System}

"Integrated data processing" describes a system which tries to eliminate duplicate processing steps by capturing bibliographic information only once, at the time the item is ordered, and updating it as necessary.

A computer record would be created when the book was ordered; this record would be changed as bibliographic information was completed, a call number was assigned, etc. It would also 
serve for circulation purposes: instead of scanning a card file to see if the book were charged the computer could be queried. This procedure would be immeasurably faster than the system herein described, unbelievably accurate, and staggeringly expensive. To date, no such system is operating successfully. It is perhaps only a matter of time until one is designed and does work; when that happens the 357 system could easily be tied into it.

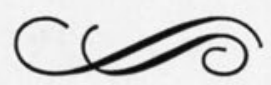

